Научная статья

УДК 331.101

DOI 10.18101/2304-4446-2021-4-84-90

\title{
ПРАКТИКА УПРАВЛЕНЧЕСКИХ ОРГАНИЗАЦИОННО-КУЛЬТУРНЫХ ИННОВАЦИЙ МЕЖДУНАРОДНЫХ КОМПАНИЙ В ЭКОНОМИКЕ ЗНАНИЙ
}

\author{
(C) Хаомин Дин \\ аспирант \\ Южный федеральный университет \\ Россия, 344006, Ростов-на-Дону, ул. Большая Садовая ул., 105/42 \\ dhm1987320@gmail.com
}

\begin{abstract}
Аннотация. Статья посвящена исследованию парадигмы экономики знаний как источника экономического роста, инновационной деятельности и повышения конкурентоспособности компании вне зависимости от ее сектора экономики. Приводятся доказательства того, что зарубежные ученые и аналитики настаивают на необходимости использования современных ресурсов, основанных на знаниях для того, чтобы обогатить экономику, привлечь больше инвестиций в компанию, повысить ее технологичность. Косвенно проводится сопоставление практики управления организационнокультурными инновациями в традиционной экономике и в экономике знаний. Раскрываются положительные экономические тенденции в деятельности компании, которые могут быть достигнуты благодаря экономике знаний: стимулы экономического и институционального развития; образованные и квалифицированные работники, способные содействовать созданию и распространению инновационных знаний; адекватная инновационная система, способная охватить глобализированные знания; информационная инфраструктура, обеспечивающая связь, доставку информации, ее обработку и получение высококачественных знаний.

Ключевые слова: инновации, управление инновациями, экономика знаний, управление знаниями, инновации международных компаний.
\end{abstract}

\section{Для цитирования}

Хаомин Дин. Практика управленческих организационно-культурных инноваций международных компаний в экономике знаний // Вестник Бурятского государственного университета. Экономика и менеджмент. 2021. № 4. С. 84-90.

Мировая экономика в начале XXI в. вступила в этап своего наиболее динамичного развития. Одним из ее признаков являются стремительная глобализация, многочисленные технологические революции. Для того чтобы не только существовать, но и успешно функционировать, устойчиво расти, приумножать капитал, современные компании должны постоянно и систематично осваивать передовые технологии, новые рынки, генерировать инновационные знания и обладать мощным человеческим капиталом. Все это может быть достигнуто благодаря следованию менеджмента компании принципам парадигмы «экономики знаний», которая получила свое развитие в конце XX — начале XXI в.

Экономика знаний представляет собой совершенно уникальную форму организации деятельности компаний и управления миром бизнеса, основными функциями которой являются воспроизводство, хранение, распространение и использование знаний [2]. Решающее значение в экономике знаний приобретает посто- 
Хаомин Дин. Практика управленческих организационно-культурных инноваций международных компаний в экономике знаний

янное и быстрое развитие навыков, твердых знаний, повышение ответственности. В таких условиях общество буквально вынуждено постоянно адаптироваться к новому, формировать людей с такой системой знаний, которая позволит им развивать собственные компетенции, полноценно интегрироваться в социокультурный контекст, в котором они живут и осуществляют свою деятельность. Собственно, все это обусловливает необходимость переосмысления практики управления организационно-культурными инновациями с учетом опыта ведущих современных международных компаний.

Инновации являются одним из самых важных элементов бизнеса вне зависимости от того, в какой сфере экономики он функционирует. В традиционной экономике было принято считать, что инновации - это нечто исключительно техническое, что характерно исключительно для больших корпораций, как результат отдельных процессов, разработок и производства. В то время, как в экономике знаний инновации начали приобретать совершенно иной смысл и рассматриваться прежде всего в контексте человеческого развития и сотрудничества.

Западные ученые М. В. Валлин и Г. Крог [15], опираясь на собственные исследования, говорят о том, что в современных компаниях процесс инноваций представляет собой планомерную деятельность, состоящую из пяти последовательных шагов (рис. 1).

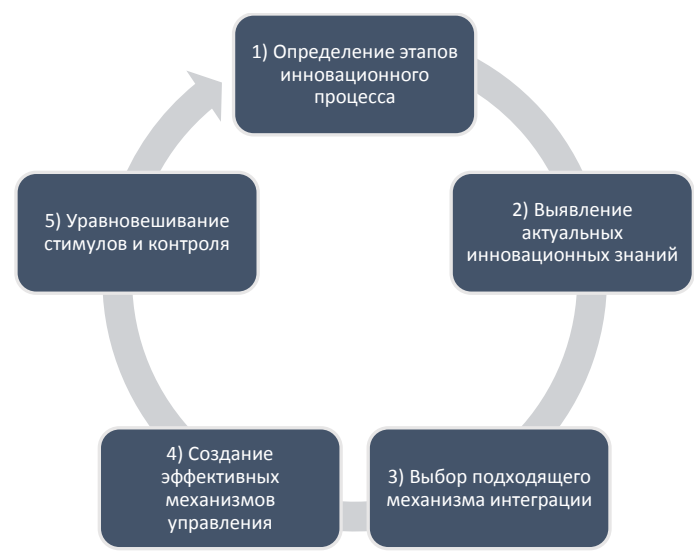

Puc. 1. Процесс реализации инноваций в международных компаниях, придерживающихся политики экономики знаний

Итак, как следует из представленной парадигмы, в международной практике инновации рассматриваются прежде всего сквозь призму возможностей человеческого капитала компании и особенностей управления им.

В современной экономике, основанной на знаниях, человеческий капитал рассматривается как отражение экономической ценности компании. Человеческий капитал, будучи наиболее важной частью интеллектуальных ресурсов компании, состоит из знаний, навыков, личностных качеств, опыта, интуиции, личных взглядов и мнений. Ни одна из компаний не может сказать о том, что она полностью владеет человеческим капиталом, поскольку сотрудники, являясь его носителями, забирают данный ресурс вместе с собой, покидая компанию [11]. Говоря 
другими словами, основу человеческого капитала составляют индивидуальные способности сотрудников, которые подвергаются соответствующему управлению для достижения целей компании.

В этом и заключается основное отличие управления человеческим капиталом в традиционной экономике и в экономике знаний. При первом подходе сотрудники рассматривались прежде всего как социальная коллективная группа и активный ресурс предприятия в то время как в экономике, основанной на знаниях, человеческий капитал понимается как навыки сотрудников, определяемые их знаниями, талантом и навыками.

Именно сотрудник, обладающий системой знаний, представляет наивысшую ценность для компании, поскольку знания являются самым действенным инструментом для получения прибыли [14]. Исходя из этого следует, что стоимость компании, кроме непосредственно ее материальных запасов, складывается также из интеллектуального капитала, основанного на знаниях ее сотрудников. Для того чтобы современная компания успешно функционировала на рынке в условиях экономики знаний, руководство должно уметь определять навыки и возможности человеческого капитала, выстраивать соответствующую систему управления для того, чтобы направлять имеющийся в распоряжении интеллектуальный ресурс на инновации $[4,8]$.

Управление человеческим капиталом как главным интеллектуальным ресурсом компании в экономике знаний выдвигается как набор взаимосвязанных друг с другом видов и форм деятельности компании, как система управления, сосредоточенная главным образом на развитии человеческого потенциала (знаний, навыков, компетенций) для генерирования профессионального опыта $[3,7,10]$. При таком подходе декларируемая ранее диада знаний, включающая когнитивную и эмоциональную составляющие, трансформируется в триаду знаний и дополняется духовной категорией $[3,5]$.

В современной парадигме экономики знаний организационное знание (или человеческий капитал) представляет собой, главным образом, взаимосвязь трех компонентов: духовные знания, эмоциональные знания и их рационализация когнитивные знания. Данный концепт в своем единстве образует настоящий фундамент знания или так называемую ДНК интеллектуального ресурса компании, ее инновационного потенциала.

Для того чтобы человеческий капитал компании работал на благо ее инновационного развития, система их знаний должна соответствующим образом управляться и направляться. Это обеспечивается посредством выстраивания действующей системы менеджмента для интеграции когнитивных знаний сотрудников, посредством организационной культуры для интеграции эмоциональных знаний, лидерства. Для этого, как отмечает Д. Д. Цыренов, может быть задействована интегрированная структура COSO, ERM как процедуры поиска стратегических альтернатив, потенциальных событий, которые могут оказать влияние на компанию, ее деятельность, риски и тому подобные факторы, которые так или иначе способствуют достижению ожидаемых результатов [1]. Однако же в современной экономике знаний данный процесс управления связывают с рядом трудностей (рис. 2). 
Хаомин Дин. Практика управленческих организационно-культурных инноваций международных компаний в экономике знаний

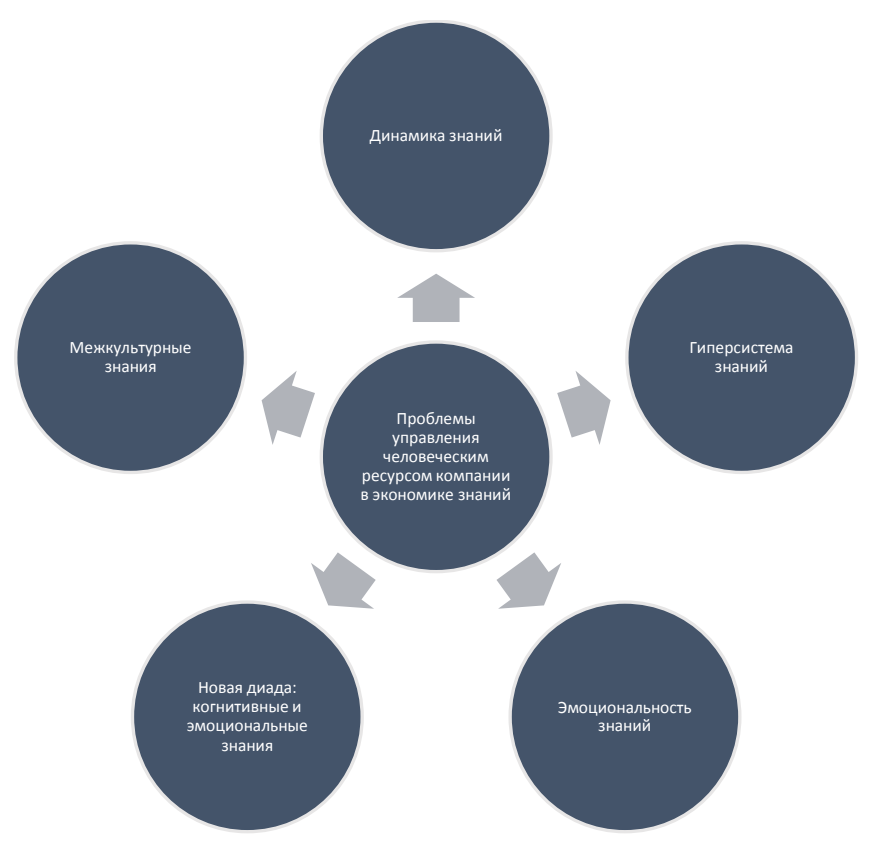

Puc. 2. Проблемы организационно-культурного управления компанией в экономике знаний (международный опыт)

Не менее решающее значение в контексте появления экономики знания сегодня имеют творчество и креативность человеческого потенциала компании. В 1999 г. об этом заявляли еще Зельцер и Бентли, говоря о четырех базовых составляющих креативности:

- способность человека формулировать новые проблемы;

- способность к передаче своих знаний в различных контекстах;

- способность учиться;

- способность преследовать конкретные цели.

При подходе, основанном на экономике знаний, становится очевидным, что творческие и креативные ресурсы сотрудников компании могут иметь решающее значение для ее инновационного развития.

История управленческой мысли и практики показывает, что творчество как фактор роста и экономического развития начало рассматриваться только лишь со второй половины XX в. В особенности данная тенденция была характерно для периода после 1950-х гг., когда среди зарубежных экономистов проблема научно-технического творчества и его роли в экономическом развитии приобрела решающий характер. Хотя, конечно же, современные теоретики экономического роста более склонны считать, что экономика - это прежде всего динамическое явление, где творчество выступает экзогенным фактором.

Творчество и творческая активность интеллектуального ресурса компании означают, в первую очередь, отказ от старого (рутина, традиции) и перенос акцента на новое (представленное инновациями, оригинальностью и разнообразием). В силу того, что молодые люди, как правило, демонстрируют особую склонность использовать новые технологии, они должны быть ориентированы на то, 
чтобы направлять свой талант на развитие своего потенциала и его творческое проявление. Один из представителей западной экономической теории Д. Тэпскотт [12, 13] в рамках своей работы под названием «Цифровое развитие: рост сетевого поколения» пришел к выводу, что именно молодые люди «форсируют» границы экономики знаний.

Чтобы понять инновационный потенциал компании и измерить ресурс ее человеческих возможностей, в мировой практике международными институтами были разработаны соответствующие инструменты и программы [9]. В настоящее время в состав данной оценки включено 109 структурных и качественных переменных, дифференцированных для 146 стран. Конечная цель сводится, главным образом, к тому, чтобы измерить их эффективность в прямом соответствии с четырьмя основными столпами экономики знаний [16]. Представим содержание измерения данного индекса схематически (рис. 3).

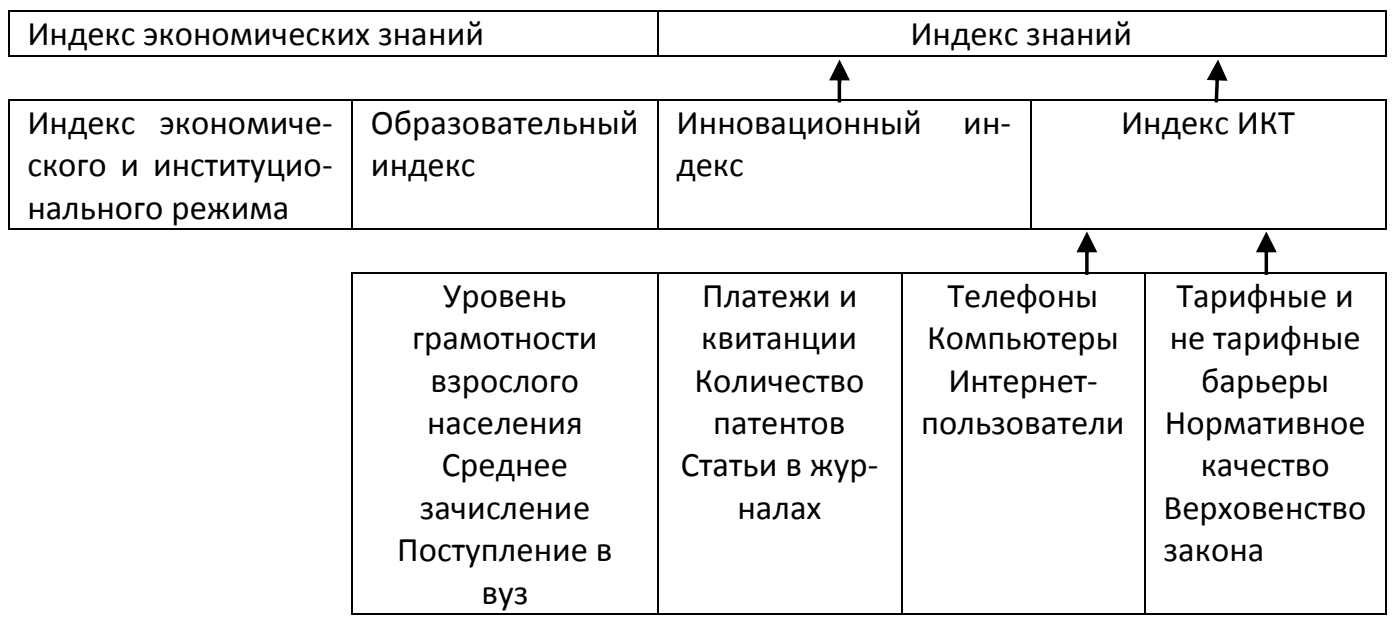

Puc. 3. Структура индекса экономики знаний и индекса знаний в современной мировой практике

Каждый из представленных в структуре рассматриваемых показателей индексов может иметь значения, равные от 0 до 10, где 10 - самый высокий ранг [6].

Таким образом, резюмируя проведенное исследование современной практики управленческих организационно-культурных инноваций международных компаний в экономике знаний, мы можем сказать о том, что информация в аспекте знания сегодня выступает главной движущей силой экономики. В таком контексте рост человеческого, интеллектуального и социального капитала, а также повышение роли творчества и креативности являются одним из ключевых факторов устойчивого долгосрочного развития компании и ее перспективы ее инновационной деятельности. Решающее значение в таких условиях имеет творческое измерение экономической деятельности, предполагающее отказ от старого (рутины и традиций) и акцентирование на новом (инновации, оригинальность и разнообразие). В современной экономике именно знания выступают самым важным стратегическим ресурсом компании. В связи с этим в своей практике управления организационно-культурными инновациями компании должны сосредоточивать- 
Хаомин Дин. Практика управленческих организационно-культурных инноваций международных компаний в экономике знаний

ся, в первую очередь, на разработке реальных стратегий знаний, что повысит также их конкурентоспособность, как внутреннюю, так и внешнюю, позволит стабильно работать и действовать в условиях неопределенности или каких-либо трудностей.

\section{Литература}

1. Рыжаков А. А., Цыренов Д. Д. Современные подходы к управлению рисками // Вектор экономики. 2020. № 12 (54). С. 47. Текст: непосредственный.

2. Цыренов Д. Д. Развитие методики оценки когнитивного потенциала региональной экономики // Вестник Бурятского государственного университета. Экономика и менеджмент. 2019. № 2. С. 82-90. Текст непосредственный.

3. Becerra-Fernandez, I., and Sabherwal, R. Knowledge management. Systems and processes. Armonk: M. E. Sharpe, 2008. Текст непосредственный.

4. Bratianu, C., and Orzea, I. The entropic intellectual capital model // Knowledge Management Research \& Practice, 2013. 11(2), 133-141. Текст непосредственный.

5. Bratianu C. Organizational knowledge dynamics: managing knowledge creation, acquisition, sharing, and transformation. Hershey: IGI Global, 2015. Текст непосредственный.

6. Chen D. H., Dahlman C. J. The knowledge economy. The KAM methodology and World Bank operations. World Bank Institute Working Paper. 2005. № 37256. Washington DC. Текст непосредственный.

7. Dalkir K. Knowledge management in theory and practice. Amsterdam: Elsevier, 2005. 372 р. Текст непосредственный.

8. Davenport H. T., Prusak L. Working knowledge. How organizations manage what they know. Boston: Harvard Business School Press, 2000. 233 р. Текст непосредственный.

9. Debnath S. C. Creating the knowledge-based economy in Kingdom of Saudi Arabia to solve the current unemployment crisis // The Ritsumeikan Business Review. 2015. 28(2). P. 249-268. Текст непосредственный.

10. Hislop D. Knowledge management in organizations. A critical introduction. Oxford: Oxford University Press. 2005. Текст непосредственный.

11. Sharabati A., Jawad S., Bontis N. Intellectual capital and businesss performance in the pharmaceutical sector of Jordan // Management Decision. 2010. 48(1), 105-131. 438 p. Текст непосредственный.

12. Tapscott D. Growing up digital: The rise of net generation. New York: McGraw-Hill. 1998. 338 р. Текст непосредственный.

13. Tapscott D. The digital economy. Anniversary Edition: Rethinking promise and peril in the age of. networked intelligence. New York: McGraw-Hill, 2014. 449 р. Текст непосредственный.

14. Thai V. V., Cahoon S., Tran H. T. Skill requirements for logistics professionals: Findings and implications // Asia Pacific Journal of Marketing and Logistics. 2011. 23(4), 553-574. 2011. Текст непосредственный.

15. Wallin, M.W., and von Krogh, G. Organizing for open innovation: focus on the integration of knowledge // Organizational Dynamics. 2010. 39(2), 145-154. Текст непосредственный.

16. World Bank. Knowledge Assessment Methodology, Retrieved from https://knoema.com/atlas/sources/WB?topic=World-Rankings (2012) (дата обращения: 9.06.2021). Текст: электронный.

Статья поступила в редакцию 26.08.2021; одобрена после рецензирования 29.10.2021; принята к публикации 01.11.2021 


\title{
PRACTICE OF ORGANIZATIONAL AND CULTURAL MANAGEMENT INNOVATIONS OF INTERNATIONAL COMPANIES IN THE KNOWLEDGE ECONOMY
}

\author{
Haoming Ding \\ Research Assistant, \\ South Federal University \\ 105/42 Bolshaya Sadovaya St., Rostov-on-Don 344006, Russia \\ dhm1987320@gmail.com
}

Abstract. The article studies the paradigm of the knowledge economy as a source of economic growth, innovations and increase of the competitiveness of a company, regardless its sector of the economy. Evidence is given that foreign scientists and analysts insist on the need to use modern knowledge-based resources in order to enrich the economy, attract more investment to the company, and improve its producibility. We made an indirect comparison between the practice of organizational and cultural managment innovations in the traditional economy and in the knowledge economy. The article shows the positive economic trends in the company's activities that can be achieved thanks to the knowledge economy: incentives for economic and institutional development, well-educated and skilled workers contributing to the creation and dissemination of innovative knowledge, an adequate innovation system covering the globalized knowledge, information infrastructure that provides communication, delivery of information, its processing and obtaining high-quality knowledge.

Keywords: innovations, innovation management, knowledge economy, knowledge management, innovations of international companies.

\section{For citation}

Haoming Ding. Practice of Organizational and Cultural Management Innovations of International Companies in the Knowledge Economy. Bulletin of Buryat State University. Economy and Management. 2021; 4: 84-90 (In Russ.).

The article was submitted 26.08.2021; approved after reviewing 29.10.2021; accepted for publication 01.11.2021. 